\title{
Pragmemes in Outdoor HIVIAIDS Campaign Messages in Benin Metropolis, Nigeria
}

\author{
Patience Obiageri Solomon-Etefia \\ University of Benin, Nigeria
}

\begin{abstract}
Outdoor HIV/AIDS campaign messages in Benin metropolis were usually coined in textual and pictorial form to aid in the sensitisation of the populace. The random research in HIV/AIDS and its campaign cannot be downplayed since the inception of the epidemic, and this is all over the world. A lot of studies have been carried out on HIV/AIDS discourse. These include studies in medicine, sociology, education, psychology as well as quantitative studies on indoor HIV/AIDS campaigns messages, with little attention paid on the analysis of outdoor campaign messages
\end{abstract}

\footnotetext{
Patience Obiageri Solomon-Etefia

Department of Linguistic Studies, University of Benin, Benin City, Nigeria

Email: patience.solomon-etefia@uniben.edu
}

Received 15 August, 2017; Revised 2 January, 2018; Accepted 15 January, 2018

Copyright @ 2018 Language Research Institute, Sejong University

Journal of Universal Language is an Open Access Journal. All articles are distributed online under the terms of the Creative Commons Attribution Non-Commercial License (http://creativecommons.org/licenses/by-nc/3.0) which permits unrestricted non-commercial use, distribution, and reproduction in any medium, provided the original work is properly cited. 
86 Pargmemes in Outdoor HIV/AIDS Campaign Messages in the Benin

especially from the pragmatic angle. This paper therefore examines the pragmatic dimensions with its focus on the textual analysis of the outdoor HIV/AIDS campaign messages. This paper aims at analysing the various distinctive practs of the messages. The data for this study were collected from thirteen outdoor HIV/AIDS campaign messages purposively selected from posters, billboards and handbills. All the collected textual HIV/AIDS campaign messages were subject to Mey's pragmatic acts theory for analysis. The study reveals that HIV/AIDS campaign messages in Benin metropolis were information-motivated discourses in social context, characterised by the practs of counselling, cautioning, advising, requesting, commanding, threatening and persuading. The practs were direct act and indirect speech acts, which made use of contextual features, such as reference, relevance, inference, shared situation knowledge and shared cultural knowledge. The paper concludes that the examination of pragmeme in outdoor HIV/AIDS campaign messages is a crucial prerequisite for understanding, communicating and managing the associated diverse challenges of HIV/AIDS in the society.

Keywords: outdoor campaigns, HIV/AIDS discourse, pragmeme, pragmatic acts, Benin metropolis

\section{Introduction}

A lot of studies have been carried out on HIV/AIDS discourse since the inception of HIV/AIDS in the 1980s. The studies that investigated HIV/AIDS campaign messages in Nigeria include (e.g., Salisu 2008; Ojeifo \& Gbakeji 2009; Olatunji \& Robbin 2011; Makinde 2013, 2014; Solomon-Etefia 2015). Makinde (2013, 2014) adopted the perlocutionary acts and the pragmatic acts theory in his textual analysis of indoor messages in Ogun State, Nigeria while Solomon-Etefia (2015) adopted the pragmatic and semiotic theory 
respectively to analyse outdoor HIV/ADS campaigns in Benin metropolis ${ }^{1}$, Nigeria. The other listed studies were based on indoor HIV/AIDS campaign messages quantitative investigation without application of theoretical frameworks. For example, Ojeifo \& Gbakeji's (2009) study of the level of HIV/AIDS awareness in four tertiary institutions in Edo State of Nigeria revealed that HIV/AIDS awareness in Nigerian Universities was quite high. A similar study by Olatunji \& Robbin (2011) found that both scary and mild expressions in campaigns are effective in arresting the spread of HIV/AIDS among Nigerian graduates. Salisu (2008) examined the communicative effectiveness of selected HIV/AIDS public awareness/sensitization texts on some civil servants at Keffi Local Government of Nasarawa State and found poor communicative effectiveness of the campaign messages due to illiteracy.

The present study examines the pragmeme of textual ${ }^{2}$ outdoor HIV/AIDS campaign messages in the Benin metropolis, Nigeria, with a view to critically analysing their various distinctive practs.

The data for this paper were collected from posters and handbills from the University of Benin teaching hospital as well as billboards on HIV/AIDS campaign messages in Benin metropolis, Nigeria. A total of thirteen (13) outdoor HIV/AIDS campaign messages, purposively selected from posters, handbills and billboards were used in this research. All the data were analysed using Mey's Pragmatic Acts Theory. It is also pertinent to state that this work is a part of Solomon-Etefia (2015).

\footnotetext{
${ }^{1}$ Benin metropolis is located approximately 25 miles longitude 5.6142558 north of the Benin River and 200 miles by road, latitude 6.4090558 east of Lagos, Nigeria. Its population is about 1,147,188, as stated by the 2006 Census (National Population Commission 2010).

2 See e.g., Jalilifar 2009, Mikhchi 2011.
} 


\section{HIVIAIDS Communication Campaigns}

The devastating nature of HIV infection has provoked countries all over the world to mount aggressive campaigns aimed at educating the people on some preventive and managerial measures towards the epidemic. One of such preventive and managerial measures is the design of awareness campaigns about HIV/AIDS.

The awareness about HIV/AIDS through campaign can transpire in various ways: usually through the electronic media, billboards, flyers and posters. It can also be through alternative ways like "inscriptions on vehicles, umbrellas, clothing, etc. Lately, with the advent of the new information and communication technology, advertising is now relayed and transmitted on the Internet, a procedure known as netvertising" (Makinde 2014: 2). Some scholarships have investigated communication campaigns generally (see e.g., Rogers \& Storey 1987, Weiss \& Tschirhart 1994, Coffman 2002, Atkins \& Rice 2013). Atkins \& Rice (2013) define campaign to include strategies for producing effects on knowledge, attitudes and behaviour across a variety of domains, including political, social and environmental as well as health outcomes. Rogers \& Storey (1987) aver that public communication campaigns use the media, messaging and an organised set of communication activities to generate specific results in a large number of individuals and in a specified period of time. Rogers and Storey elaborate on two strategies of communication campaign: the air and ground strategies. The air is typically the public media campaign while the ground strategy utilizes community-based communication or grassroots organising. An example of ground strategy is the one involved in the challenge of reducing the risk of HIV transmission among ethnically diverse, high risk populations, and so on. This type of campaign uses 
small media materials, posters, and trusted community members to relay its messages since air strategy alone would not have worked (Rogers \& Storey 1987).

The nature of every communication campaign is geared at persuasion, that is, the purposive effort of persuading the populace. Pragmatically, communication campaign could denote an act commenced for a cause. Thus, it can be exemplified by the writer of the outdoor HIV/AIDS campaign messages, who writes a message that is expected to perform certain functions on the target populace (i.e., readers or hearers), which is the focus of this paper.

\section{The Contexts of Outdoor HIVIAIDS Campaign Messages}

The importance of context in outdoor HIV/AIDS campaigns cannot be understated. Scholars over the years have developed interest in the issue of context (see e.g., Levinson 1979, 1983; Thomas 1995; Palmer 1996; Yule 1996; Mey 2001). Mey (2001: 39) argues that contextual perspectives have either been in linguistic terms, in which case, context refers to previous subsequent linguistic material in a text, or extra-linguistic terms of continually changing surroundings in the widest sense that enable the participants in the communication process to interact intelligibly. The concept of context has been measured as the totality of the environment in which a word is used (Mey 2001). Thus, context in the actual sense helps in the interpretation of word in any environment of discourse. Odebunmi (2006) avers that context is the backbone of meaning. Malinowski (1923/1946) and Firth (1962) were the first scholars to 
introduce the context of situation in contextual discourse. They were concerned with stating meanings in terms of the context in which language is used. However, other scholars looked at context from different angles. Adegbite (2000) distinguished two types of context, which include the verbal and situational context. The verbal context is functional in the interpretation of linguistic items in terms of their association with one another while the situational context applies to the participants' shared knowledge in communication or interaction. In agreement with Adegbite (2000), Odebunmi (2006: 240) claims that context is evident at two levels, viz. at the language level and the situation level. At the level of language, meaning is considered as having a possibility potential if the same language of communication is at the disposal of interactants while at the situational level, assumptions are held on the basis of the shared code (linguistic or non-linguistic) and the experience of the interlocutors. He opines that the three important features or aspects of context are (i) shared knowledge of topic or subject, (ii) shared knowledge of word choices, referents and references, and (iii) shared socio-cultural experiences, previous or immediate (SCK). In summary, context is the totality of the situations in which a text comes to life. It is an abstract category employed by language scholars to provide a link between linguistic items, the social and situational factors of communication (Adeniji \& Osunbade 2014). (Also see Salmani Nodoushan 2015a, 2015b; Capone 2016; cited in Solomon-Etefia \& Nweya 2017).

The notable contextual features of outdoor HIV/AIDS campaign message in Benin metropolis is the textual. Thus, message providers apply these features, through the use of language to make references to African society and culture in order to achieve success. These contextual features serve as a means of communication to the reader(s) directly or indirectly. Therefore, the analysis of the 
pragmatic acts of HIV/AIDS campaign messages in the Benin metropolis is context dependency.

\section{Theoretical Framework}

Jacob Mey's Pragmatic Acts Theory is adopted for the interpretation of the data in this study. Gu (1993) introduced the pragmatic acts as a concept before it was established as the Pragmatic Acts Theory by Mey in 2001 as a substitute for Austin's (1962) speech acts, which he claims "lacks a theory of action" and is "non-situated" (Aremu 2015). Thus, one would say that this theory is motivated by the criticism of the speech acts theory by Fairclough (1989) and Mey (2001). According to Fairclough (1989: 9), the speech act theory is seen as an 'atomistic' and as a 'thought wholly emanating from the individual'. On the other hand, Mey (2001: 2014) avers that the theory lacks action and situation. Mey's pragmatic acts theory suits the analysis of the data in this paper because it is a function-based approach to the study of meaning, an action and situated based theory that interprets data based on contextual knowledge. According to Mey (2001: 221), a pragmatic act is instantiated through an "ipra" or a "pract", which realizes a "pragmeme" as "every pract is at the same time an allopract, that is, a concrete instantiation of a particular pragmeme". In real meaning, what decide a pract is solely participants' knowledge of interactional situation and the potential effect of a pract in a particular context; thus, Odebunmi (2006) argues that "practing resolves the problem of telling illocutionary force from perlocutionary force". The focus (of pragmatic act) is on the interactional situation in which both speakers and hearers realize their aims. "The explanatory movement is from 
92 Pargmemes in Outdoor HIV/AIDS Campaign Messages in the Benin

the outside in, rather than from the inside out: Instead of starting with what is said, and looking for what the words could mean, the situation in which the words fit is invoked to explain what can be (and is actually being) said" (Mey 2001: 751). The "implied identification" is central to Mey's pragmatic acts, in the sense that, the importance is not on the "said" but the "unsaid". The hearer is usually influenced (set up) to see the speaker's act, as no act is explicitly made. In particular, there is no speech act to indicate a pragmatic act. The only way to identify a pragmatic act, therefore, is to be on the lookout, or listen to it. There are two components concerned in the realization of a pragmeme in the pragmatic act theory: the textual part and the activity part. The activity part characterizes the options such as speech acts, indirect speech acts, conversational ('dialogue') acts, psychological acts (emotions), prosody (intonation, stress) physical acts, etc. that are available to the speaker to perform the various functions he so desires. The realisation of the pragmatic function (pract) in a given communicative event centres on the textual parts, especially in the communication of the speaker's intention; in any case, he may employ the 'inf' which stands for inference, the 'ref' for reference, 'rel' for relevance, 'vce' for voice, 'ssk' for shared situational knowledge, 'sck' for shared cultural knowledge 'mph' for metaphor, or ' $\mathrm{m}$ ' for metapragmatic joker. Thus the activity part rely on context for the meaning realization of any discourse by interactants. Presented below is a schemata on the pragmatic acts theory.

In the Figure 1, the list to the left comprises those choices that are open to the language user in communication. The cells can be either filled or empty. One or more of these available options can be chosen by the language user. When all the cells are empty, then, the matrix runs to zero, which is represented on the schemata as ' $\varnothing$ ' (NULL). 
An instance of this situation may be the case of silence. This is not the same as zero or no communication. The features to the right of the schemata represent options that are available in the contextual chain; these are contextual features that influence communication.

Figure 1. Pragmeme (Mey 2001: 222)

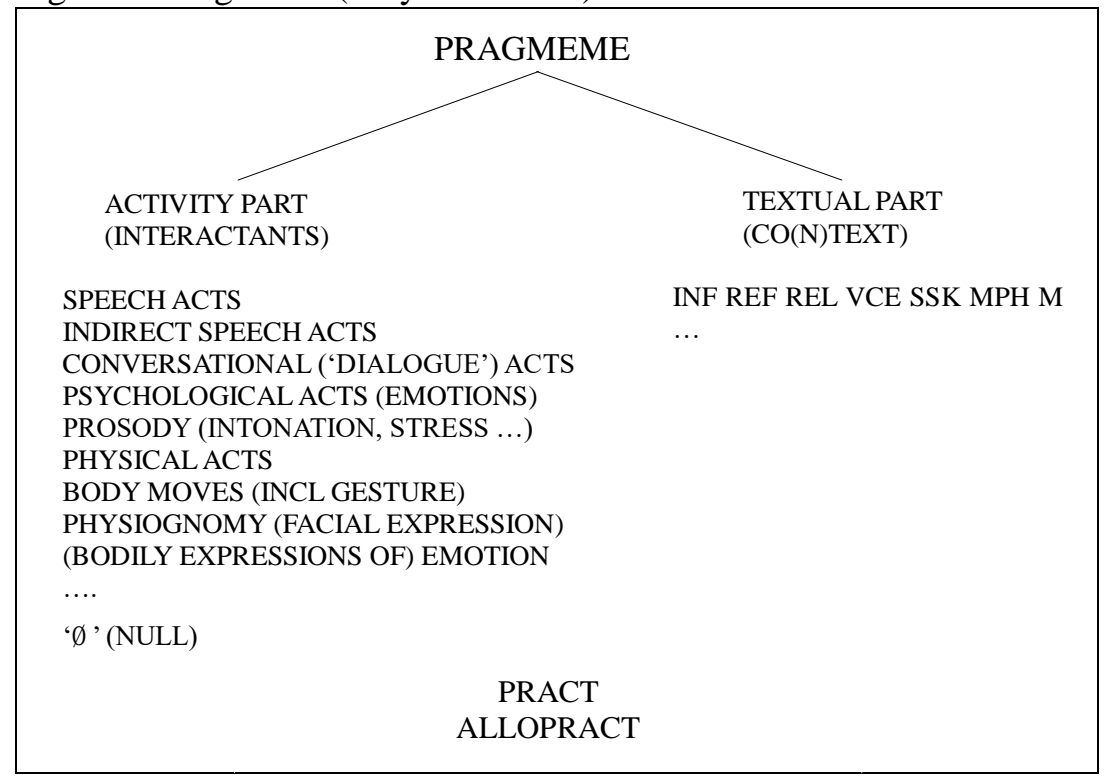

However, the fused nature of the selected textual HIV/AIDS campaign messages, which is an information-motivated discourse, involves actions which help to reveal the intentions of the writers. Thus, the analysis cannot be best achieved with speech act theory because speech act strictly deals with utterances. Nonetheless, when the utterance carries with it other supporting acts such as gestures, intonation, body postures, etc. on which it essentially depends for success, it requires a more demanding theory like pragmatic act. These other extra linguistic elements, Kecskes (2010) suggests, will 
94 Pargmemes in Outdoor HIV/AIDS Campaign Messages in the Benin

have bearing on the speakers and the hearers. In line with Mey (2001), this investigation reveals that it is not possible for speakers to engage in all the elements indicated in the activity part at all times, hence the direct speech acts and the indirect speech acts were utilised in the analysis of the textual component of this study.

\subsection{On the Pragmeme of HIV/AIDS Campaign Messages}

The pragmeme of HIV/AIDS campaign messages in Benin metropolis exists in a social context, which is a informationmotivated discourse between the message providers and the target populace. In Mey's (2001: 221) idea, pragmeme is seen as a "generalised pragmatic act" while Capone (2005: 1355) views it as "speech acts in context". At the pragmeme level of this analysis, the two acts utilised were the direct speech acts and the indirect speech acts $^{3}$. These acts interact with the contextual features via reference (REF), inference (INF), shared situational knowledge (SSK) or shared cultural knowledge, euphemism (EPH), and relevance (REL) to establish the practs such as counselling, cautioning, threatening, and persuading in the textual HIV/AIDS campaign messages.

\footnotetext{
3 The direct speech acts exhibit directness of purpose. That is, they are acts that are direct in terms of the relationship between what the message providers write and what they mean or intend. Osisanwo (2003: 65) describes thisas the correlation between the structure and the function of the structure where this relationship is grammatically established, the utterance amounts to a direct speech act. Searle (1969: 19) describes an indirect speech act as: "One performed by means of another," which means there is no correlation between the structure and function, presupposing that the intended messages are implicit. (Cf. Capone 2016).
} 


\section{Data Analysis}

The data in this paper were not classified according to their various practs headings, but based on the campaign messages. Those in the first category are messages that are accounted for by the indirect speech acts. The second category is for those accounted for by the direct acts. In the Benin metropolis, the outdoor HIV/AIDS campaign messages are designed in such a way that the indirect messages are often followed by direct messages.

\section{(1) Message $1^{4}$}

a. With full support from my family, I live a positive life with HIV

b. Talk to a trusted member of your family, Support group or friend about your status

Messages ( $1 \mathrm{a} \& \mathrm{~b})$ above are on the action project poster on HIV/AIDS entitled 'HIV and disclosure'. It is with a graphic illustration to help catch the attention of the audience. In the caption, a HIV patient embraces two of his family members. The first message (i.e., 1a) points out the feeling of a HIV patient who expresses joy that he can live a positive life with the support of his family members. The second, message (1b), advises the HIV patient on the need to disclose his or her HIV status to the trusted members of his or her family, support group as well as friends who can help him or her live a positive life. The messages ( $1 \mathrm{a} \& \mathrm{~b})$ try to co-opt the target audience on the need to fight against stigmatisation and

\footnotetext{
${ }^{4}$ The Sources of the analysed messages (from Message 1 to Message 13) are shown in Primary Sources in Reference.
} 
96 Pargmemes in Outdoor HIV/AIDS Campaign Messages in the Benin

discrimination of people living with HIV/AIDS. This is because, once a patient discloses his/her status, and his/her family and friends accept, and support him/her, living longer even with the disease, is sure.

The practs of these messages are persuading and advising. With the application of SSK, it persuades and advises the audience to support family members living with HIV/AIDS. Although the coopting element is implicit, not explicit, in the message, with SSK, the populace are able to infer the practs. Through the use of the referent pronouns "your" and "my", the audience is co-opted. The messages are understood and effective to the audience who has understood the importance of supporting their family members living with HIV/AIDS instead of running away from them.

(2) Message 2

a. Do not isolate a positive child

b. Children living with HIV need your care, love and support to:

- Live positively

- Build confidence

- Grow to Adulthood

Messages ( $2 \mathrm{a} \& \mathrm{~b})$ above, use a graphic illustration to catch attention. There are two women and a child from a distance steering and mocking another child, who is believed to be HIV-positive. This message is on action project poster on HIV/AIDS labelled "avoid stigma and discrimination". Message (2a): "do not isolate a positive child", informs the populace on the need to interact with a HIVpositive child instead of isolating him, which creates stigma and discrimination. Message (2b): "children living with HIV need your care, love and support to live positively, build confidence and grow 
to adulthood" persuades the audience on the need to care, love and support children living with HIV, so that the children can live a normal and positive life to adulthood. It is often times believed that most of these children lost their parents as a result of this ailment and, if they are not cared for, their future is jeopardised. The pract of this message is persuading because it takes a convincing power in addition to applying the SSK to make this message effective, so that the target audience does not discriminate against children living with HIV/AIDS. Thus, the target population are implicitly co-opted into the message to work on their psyche relying on the SSK, with the use of subtle words like "care", "love" and use of the pronoun "your".

(3) Message 3

Heart to Heart

We listen, we care

This message contains two ideas, which consist of two acts: the indirect speech act and the direct speech act. The writers tend to capture the attention of the audience with the indirect speech acts before relaying the real message in the direct speech act.

This is the message found at every counselling unit of HIV/AIDS, hence source of the message was a poster from the counselling centre, with a graphic illustration to help catch attention. The graphic captures two images of people facing each other with an impression that one is counselling the other. The amazing thing is that counselling and test for HIV are conducted there but the message does not indicate that one can run a HIV test there. This message could be interpreted as "come for your HIV test, we are at your service" or "come for HIV test, we listen and care for you", which is implicit; that is, it is indirectly communicated to the reader(s). But 
98 Pargmemes in Outdoor HIV/AIDS Campaign Messages in the Benin

the message simply says "Heart to Heart", which could imply an emotional heart to heart discussion as lovers. However, the intended directive act of this indirect act is "come for counselling and HIV test; we are at your service" with a presupposition that the counsellors will always listen and care for you as their patients since it is their obligation to render the service. "Heart to Heart" could also imply confidentiality on the part of the counsellors.

The direct part of the message "we listen, we care" still does not reveal any message on or issues on HIV/AIDS either running a test or counselling on HIV. So, in terms of communicative efficiency, the message seems to have lost its essence. It was supposed to be a message that directly informs the reader(s) where to run HIV test, but nothing of such was mentioned in it. However, with the application of SSK, which is information-motivated, the populace are able to infer the pract of the message as counselling, because the intended motive of the writers was to tell to the reader(s) that, before any HIV test is run, there should be proper counselling. That is why the message is usually placed at the counselling unit. But the implicitness of the communicated intention made it more complex and ineffective to the people in the metropolis. Another complex issue is that the directive act of the message, which is "we listen, we care", does not make reference to any issue on the running of HIV/AIDS test owing to its indirectness.

(4) a. Message 4a

Love carefully

AIDS has no cure

This message uses an image illustration to help catch attention on the action project handbill on HIV/AIDS. It contains two acts - an 
indirect speech act and a direct speech act. The writers tend to capture the attention of the audience with the indirect speech act before relaying the real message in the direct speech act. As an indirect message, "love carefully" cautions the reader(s) that, in love affairs, whether emotional or agape love, they should be very careful, having it at the back of their minds that AIDS exists and HIV can be contracted from that person they claim to love. If contracted, it has no cure. This made the writer to back up the first part of the message with the direct act "AIDS has no cure" to show the essence of the message, which is creating the awareness that AIDS cannot be cured.

This message, at least, has helped to create awareness to the public that AIDS has no cure. The pract of this message is cautioning. With the application of SSK, the message cautions the public on the danger of not loving carefully. Thus the message may have an inferential effect on the populace.

(4) b. Message 4b

Join Nigerian in the Fight against AIDS

This message is part of (4a), which reads: "Love carefully, AIDS has no cure". It is a direct speech act to exhibit directness of purpose and intention to the audience. The message requires the entire public to join in the fight against AIDS, a disease which has no cure. Thus, the fight against this deadly disease is not for one person or just the government; but it includes the family, school and the entire public. The first part of the message in relation to the second one infers that a Nigerian family should have prevented the spread of HIV/AIDS by knowing their status before marriage. Thus, if one loves carefully, one would try to know one's HIV status and avoid risky behaviours that would spread HIV. With the application of the co(n)-texts, SSK 
100 Pargmemes in Outdoor HIV/AIDS Campaign Messages in the Benin

and SCK, the pract of this message is requesting, because it invites the audience to join their nation (Nigeria) in the fight against HIV/AIDS. This implies that the fight against HIV/AIDS is not for the government alone.

(5) a. Message 5:

Zip Up

The message (5a) above is a USAIDS/Action project pamphlet. It captures two counsellors with phones, which shows that they are ever ready to advise or help the audience who seek help on how to abstain from sex. It is an indirect speech act with a direct counterpart. The indirect speech act shows no correlation between the structure and function of the message, which means the intended message is implicit (that is not given a clear explanation). Thus, it is quite different from the intention of the message. The writers tend to capture the attention of the audience with the indirect speech acts before relaying the real message in the direct speech act. The direct act exhibits directness of purpose and intention to the audience. They are direct in terms of the relationship between what the message writes and what the intention is. This message "Zip up" is accompanied with various direct speech acts, which are embedded in "reasons to delay sex till marriage". Of all the reasons, the one that mostly concerns this research is the fifth, which states thus:

(5) b. I could contract a sexually transmitted infection like HIV. HIV infection does not show on the face. The fact that someone looks healthy does not mean they are free from sexually transmitted infections; they may not even know they are infected. 
This message counsels the audience on the need to abstain from sex to avoid contracting HIV, which does not show on the face. Thus, both combine to form the pract of this message which is counselling because it counsels the audience on the need to abstain from sex before marriage or outside marital homes. Also, this direct speech act explains the fact that HIV does not show on the face, while the indirect speech act, which captures the attention of the audience, provides motivation for justification of the direct speech.

In terms of interpretation, the message seems effective owing to the direct message that accompanies it, which is explanatory. What makes the message self-explanatory is the physical process of zipping up and down. Also, with the application of the contextual SSK, it could easily be inferred that the message counsels the youth on abstinence and faithfulness to partners for the married. The pictorial aspect of message 5 captures a young man and a young lady; both of them were having a phone fixed to their ears, a sign of making or answering a call. Their outlook expresses the fact that they are counsellors who are always on line to help or counsel clients on abstinence from sex.

(6) Message 6

Sexually transmitted infections (STIs):

a. Do you have sores, bumps, discharges/drippings, itching or burning pain around or inside your private part?

b. If you have any of these symptoms, stop having sex for now. You and your partner should visit any government or Action Supported Treatment Site below and speak to a healthcare provider immediately.

Message $6(\mathrm{a} \& \mathrm{~b})$ above are from action project poster on 
102 Pargmemes in Outdoor HIV/AIDS Campaign Messages in the Benin

HIV/AIDS. They direct speech act messages which uses image illustration to help catch the attention of the reader. These messages exhibit directness of purpose and intention to the audience. The acts are direct in terms of the relationship between what the message says and what the intention is. The first image captures a man and a woman, probably husband and wife, with STIs. The man is in pains, with his hands close to his genital part, while the woman is also in pains with her hands on her abdomen, which suggests that she is having abdominal pains. The second part of the message features the partners in front of a doctor (counsellor) at the health centre or hospital.

This message also gives the impression that HIV/AIDS is STIs which can be contracted through sex. However, in message (a), the populace are enlightened on the symptoms of STIs (Sexual Transmitted Infections), which are burning, sores, discharges and so on inside the genitals, while message (b) gives a direct counsel to the audience on what to do, which is a visit to a health care provider. Thus, the pract of this message is counselling. These messages are direct messages that explain everything the audience needs to know. They carry both the motivation and justification for the messages that yield to pragmatic practs of counselling. The message appears to be communicative. With the application of SSK, it is easy to make reference to the important aspects of the messages; namely, the symptoms of the disease and visit to a doctor.

(7) Message 7

Safer injection prevents infections

a. Used syringes and needles can spread infections

b. Do not use them 
The above 7th (a \& b) HIV/AIDS campaign message are from USAIDS poster on HIV/AIDS, just like message (6), The are direct speech act messages, which uses graphic illustrations to capture the attention of the reader. These messages exhibit directness of purpose and intention to the audience; the acts are direct in terms of the relationship between what the messages are and what the intentions are. The image on the poster has the hand of someone with syringes fixed on a flesh to show that it is in use. The message "safer injection prevents infections", with its other messages (a) \& (b), warns the audience on the need to avoid using unsterilized syringes and needles, which also spread HIV, apart from sex. The (a) message stresses that used syringes and needles can spread infection, while the (b) part of the message cautions the reader not to use them. The message is a direct speech act that gives directive to the reader; it contains both the motivation and justification for the message in the directive, which are very explanatory. This directive act helps the message to achieve its pract, which is cautioning, because it cautions on the need to avoid the usage of unsterilized syringes and needles which are not safe, and are capable of spreading infection. This message is more effective through the application of the SSK.

The message suggests that the avoidance of unsterilized syringes and needles can curb the spread of HIV, just like abstinence from sex can also curb the spread of HIV. The effectiveness of this message lies in the fact that much of the information could be inferred from the message that syringes and needles should not be shared.

(8) Message 8

Prevention of mother-to-child transmission

a. HIV/AIDS is the concern of every family

b. Talk to your health-care provider today 
104 Pargmemes in Outdoor HIV/AIDS Campaign Messages in the Benin

This message is a direct speech act on prevention of mother-tochild transmission found on action project poster. It uses graphics for illustration. As a direct message, it exhibits directness of purpose and intention to the audience. The message suggests that the woman (wife) may be pregnant and HIV-positive at the same time. She is accompanied by her husband who may also be HIV-positive to find out how to prevent the unborn child from transmitting HIV from the mother. However, the (a) message enlightens the reader that HIV/AIDS is the concern of every family. The message implicitly counsels the reader on the need to know one's HIV status. Hence, every member of the family is expected to know his or her HIV status and also show concern to the other party or others in the family when the need arises, just like what the man does by accompanying the woman (his wife) to see a healthcare provider. The (b) part of the message advises the reader on the need to visit or to talk to their health care provider when the need arises or when necessary, as the couple visits the health care provider, to seek counsel on how to prevent their unborn child from HIV transmission from the mother.

As noted above, the message is a direct speech act because it is quite explanatory. It contains the motivation and justification for the directive acts for the reader with the application of SSK. Also, the contextual SSK has helped the writer of the message to achieve the pract of the message, which is counselling. The readers could infer from the message the need to prevent mother-to-child transmission of HIV/AIDS by visiting or talking to the right healthcare provider when necessary. This message seems effective given that it can easily be understood that the message makes reference to the prevention of mother-to-child transmission of HIV/AIDS and the need for mothers or parents who are HIV-positive to visit the health care provider 
when pregnant.

(9) Message 9

Skin to skin can kill

HIV/AIDS is everywhere!

The text 9 above found on billboard advert on HIV/AIDS contains two message units, which constitute two acts without an image for illustration: the indirect speech act "skin to skin can kill" and the direct speech act "HIV/AIDS is everywhere". The indirect speech act shows no correlation between the structure and function of the message, which means the intended message is implicit (that is not given clear explanation). Thus, it is quite different from the intention of the message. The writers tend to capture the attention of the audience with the indirect speech acts before relaying the real message in the direct speech act. The direct act exhibits directness of purpose and intention to the audience. In this case, the acts are direct in terms of their relationship between the written message and what the intention is. The message cautions the people on the need to avoid direct sexual contact because one may end up contracting HIV/AIDS, which is everywhere. As HIV/AIDS is everywhere, there is need to protect oneself. The pract of this message is cautioning. With the application of SSK, the target populace were able to infer from the message a caution on the risk behind unprotected sex despite the implicitness of the indirect counterpart of the message. The indirect counterpart provides motivation and justification for the direct counterpart "HIV/AIDS is everywhere". This directive speech act carries the main point of the message on HIV/AIDS. The indirect and direct acts employ the co(n)-text SSK, which helps the writer to achieve his pragmatic goal (function) that cautions for a positive 
106 Pargmemes in Outdoor HIV/AIDS Campaign Messages in the Benin

change in the attitude and behavioural pattern of the reader(s).

(10) Message 10

Play Safe

This message is one of the HIV/AIDS messages used nationwide in Nigeria. It was used here by the Edo State Action Committee on AIDS. It contains a graphic illustration of a footballer with the ball to help catch attention. In this message, sex is presented as a game and safe as protection, implying that the audience needs to have a protected sex. However, the message could have several interpretations:

(11) a. Play safe by protecting yourself with the use of condom when you want to have sex with an unknown sex partner.

b. Play safe by being faithful to your spouse or abstain if possible.

This message is an indirect speech act. It does not exhibit the directness of the purpose and intention of the message to the audience. As an indirect speech act, there is no correlation between the structure and function of the message. Its pract is cautioning. With the application of SSK, the audience could infer from the message on the need to avoid unprotected sex, which is a gateway to contracting HIV.

(12) Message 11

Protect yourself and your partner from HIV

i. Be faithful to your partner while driving out the road and away from home 
ii. If you must have sex, always use a condom to avoid HIV and other sexually transmitted infections (STIs)

iii. Use a condom to prevent your partner at home from being infected

iv. Avoid taking too much alcohol because it can affect your judgment and may make you have unprotected sex with some one

The message 11 above is on action project and institute of human virology HIV/AIDS poster titled protect yourself and your partner from HIV. The poster actually stresses the $\mathrm{ABC}$ prevention campaign messages, with emphasis on faithfulness to one's partner and the use of condom. There was no reference at all to the first part, which is abstinence from pre-marital sex. However, there is a fourth message, which is the (iv) part of the message, which discourages taking too much alcohol. This textual message emphases the ABC messages (Abstinence, faithfulness to one's partner, and the use of condom) for protection from STIs. This message is a direct speech act, which uses graphic illustrations to capture the attention of the reader. Thus, the messages exhibit directness of purpose and intention to the audience; the acts are direct in terms of the relationship between what the messages are and what the intentions are. It contains both the motivation and justification for the message in the directive, which are very explanatory. This directive act helps the message to achieve its pract, which is commanding and requesting, because the first part of the message gives a command to the audience on the need to be faithful to their partners while the second part invites the audience to patronise or support condom use as a necessary tool to curbing HIV. This message is more effective through the application of the SSK. 
108 Pargmemes in Outdoor HIV/AIDS Campaign Messages in the Benin

(13) Message 12

a. HIV/AIDS has no cure

b. AIDS kills

c. AIDS is real

The Outdoor HIV/AIDS campaign messages 12 above are on a poster sponsored by action project and activity of the institute of human virology, Nigeria, CDC, Nigerians and Americans in partnership to fight HIV/AIDS. It stresses the existence of HIV/AIDS. The (a) make the audience to know that the disease has no cure. The (b) points out to them that the disease kills, and the (c) emphases that the disease is real. The messages are direct speech acts where the messages exhibit directness of purpose and intention to the audience; the acts are direct in terms of the relationship between what the messages are and what the intentions are. The pract of the message is threatening because it threatens the audience that HIV/AIDS is incurable, kills and real. The application of the contextual SSK and SCK enables the respondents infer that HIV/AIDS is a deadly disease.

(14) Message 13

a. Help fight AIDS ... save lives

b. Support the fight against HIV/AIDS

c. Counter the impact of AIDS today

d. Prevent HIV/AIDS from spreading

e. Stop stigma! Stop AIDS!!

f. Stop AIDS, keep the promise

g. Fighting AIDS to Finish

The messages (13) above are messages on a poster sponsored by 
action project and activity of the institute of human virology, Nigeria, CDC, Nigerians and Americans in partnership to fight HIV/AIDS. These messages caution and persuade the populace on the need to "help", "fight", "stop", "support", "finish", and "prevent" HIV/AIDS in the metropolis. The pract of these messages is more of persuasive, since the messages induce the people on the need to eradicate HIV/AIDS completely. The words used are also presuppositional element indicating that HIV/AIDS really exists. Thus, through the support of the populace, HIV can be curbed. Based on the application of the contextual SSK and SCK, the populace could infer that HIV/AIDS as a deadly disease.

\section{Findings and Conclusion}

So far, this paper has critically analysed outdoor HIV/AIDS campaign messages in the Benin metropolis, Nigeria. The paper routes its analysis with insights from Mey's pragmatic acts theory of pragmeme. The findings reveal that outdoor HIV/AIDS campaign messages in Benin metropolis are information-motivated discourses in social context. Thus, the various practs of the campaign messages are counselling, cautioning, commanding, requesting, advising, persuading and threatening. These practs are in direct and indirect speech acts, which interact with the contextual features of shared situational knowledge (ssk), shared cultural knowledge (sck), inferences (inf) and references (ref). Also, the analysis of HIV/AIDS campaign messages from pragmatic perspective has exploited both the interpretation and demonstration of the meanings in the campaign messages.

The collaboration between the information-motivated discourses 
110 Pargmemes in Outdoor HIV/AIDS Campaign Messages in the Benin

representation of outdoor HIV/AIDS campaign messages and its pragmatic analysis has provided useful information that would assist in the communication of outdoor HIV/AIDS campaign messages to the populace in the metropolis. Through this analysis, outdoor HIV/AIDS campaign messages would facilitate HIV/AIDS enlightenment and communication, which would help to prevent the spread of the endemic. It is recommended that further works on campaign messages in Benin metropolis should focus on cognitive ${ }^{5}$ pragmatics.

\section{References}

Adegbite, W. 2000. Pragmatics: Some Basic Principles and Procedures. In A. Babajide (ed.), Studies in English Language 60-80. Ibadan: Enicrownfit.

Adeniji, A. \& N. Osunbade. 2014. Pragmatic Functions of Traditionmotivated Discourses in Ahmed Yerima's Ajagunmale. International Journal of English and Linguistics Research 2.2, 114.

Aremu, M. 2015. A Pragmatic Analysis of Nigerianism in the English Usage in Soyinka's Death and the King's Horseman. Papers in English and Linguistics (PEL) 2, 75-102.

Atkins, C. \& R. Rice. 2013. Advances in Public Communication Campaigns. In E. Scharrer (ed.), The International Encyclopaedia of Media Studies Vol. V: Media Effects/Media Psychology 526-551. London: Wiley-Blackwell.

Austin, J. 1962. How to Do Things with Words. Oxford: Clarendon

5 See Chang 2007. 
Press.

Capone, A. 2005. Pragmemes. A Study with Reference to English and Italian. Journal of Pragmatics 37, 1355-1371. (https://doi.org/10.1016/j.pragma.2005.01.013)

Capone, A. 2016. Slurring in Indirect-reporting. International Journal of Language Studies 10.4, 19-36.

Chang, V. 2007. A Cognitive-pragmatic Approach to Discourse Topic: A Cross-linguistic Analysis and Universal Account. Journal of Universal Language 8.1, 1-27. (https://doi.org/10.22425/jul.2007.8.1.1)

Coffman, J. 2002. Public Communication Campaign Evaluation: An Environmental Scan of Challenges, Criticisms, Practice, and Opportunities. Cambridge, MA: Harvard Family Research Project.

Fairclough, N. 1989. Language and Power. London: Longman.

Firth, J. 1962. A Synopsis of Linguistic Theory. Oxford: Basil Blackwell.

Gu, Y. 1993. The Impasse of Perlocution. Journal of Pragmatics 20, 405-432.

Jalilifar, A. 2009. Thematic Development in English and Translated Academic Texts. Journal of Universal Language 10.1, 81-111. (https://doi.org/10.22425/jul.2009.10.1.81)

Kecskes, I. 2010. Situation-bound Utterances as Pragmatic Acts. Journal of Pragmatics 42, 2889-2897.

Levinson, S. 1979. Activity Types and Language. Linguistics 17, 365-399.

Levinson, S. 1983. Pragmatics. Cambridge: CUP.

Makinde, T. 2013. A Pragmatic Investigation of HIV/AIDS Social Management Advertisements in Ogun State Nigeria. Unpublished MPhil Dissertation, University of Ibadan. 
112 Pargmemes in Outdoor HIV/AIDS Campaign Messages in the Benin

Makinde, T. 2014. Pragmatic Acts in HIV/AIDS Social Management Advertisements. Linguistik Online 67.5, 1-24. (http://dx.doi.org/10.13092/lo.67.1600)

Malinowski, B. 1923/1946. The Problems of Meaning in Primitive Languages. In C. Ogden \& I. Richards (eds.), The Meaning of Meanings: A Study of the Influence of Language upon Thought and of the Science of Symbolism 296-336. New York: Harcourt, Brace \& World, Inc.

Mey, J. 2001. Pragmatics: An Introduction. Oxford: OUP.

Mikhchi, H. 2011. Standards of Textuality: Rendering English and Persian Texts Based on a Textual Model. Journal of Universal Language 12.1, 47-74. (https://doi.org/10.22425/jul.2011.12.1.47)

National Population Commission. 2010. 2006 Population and Housing Census: Priority Table Volume IV - Population Distribution by Age and Sex, States and Local Government Areas. Abuja: Federal Republic of Nigeria.

Odebunmi, A. 2006. Meaning in English: An Introduction. Ogbomosho: Critical Sphere.

Ojeifo, M. \& J. Gbakeji. 2009. Analysis of Spatial Awareness of HIV-AIDS among Students of Tertiary Institution Edo State, Nigeria. Ethno-Med 3.2, 153-158.

Olatunji, S. \& A. Robbin. 2011. Investigating into Undergraduates' Preferred Expression for HIV/AIDS Eradication Campaigns. Journal of Social Sciences 26.3, 195-201. (https:// doi.org/10.1080/09718923.2011.11892896)

Osisanwo, W. 2003. Introduction to Discourse Analysis and Pragmatics. Lagos: Femolus-Fetop Publishers.

Palmer, F. 1996. Semantics. Cambridge: CUP.

Rogers, E. \& J. Storey. 1987. Communication Campaigns. In C. Berger \& S. Chaffee (eds.), Handbook of Communication 
Science 817-846. Newbury Park, CA: Sage.

Salisu, M. 2008. Public Awareness and Sensitization Campaigns on HIV/AIDS in Nigeria. Journal of Pan African Studies 2.4, 215224.

Salmani Nodoushan, M. 2015a. Review of Intercultural Pragmatics. Pragmatics \& Society 6.1, 152-156. (http://doi.org/10.1075/ ps.6.1.08nod)

Salmani Nodoushan, M. 2015b. The Secret Life of Slurs from the Perspective of Reported Speech. Rivista Italiana di Filosofia del Linguaggio 9.2, 92-112. (http://doi.org/10.4396/201512204)

Searle, J. 1969. Speech Act: An Essay in the Philosophy of Language. Cambridge: CUP.

Solomon-Etefia, P. 2015. A Pragma-semiotic Investigation of Outdoor HIV/AIDS Campaign Messages, Benin Metropolis, Nigeria. Ph.D. Dissertation, University of Ibadan.

Solomon-Etefia, P. \& G. Nweya. 2017. A Pragma-semiotic Analysis of the Catholic Bishops' Communiqué on the Ebola Epidemic: Impact on the University of Ibadan Catholic Faithful. International Journal of Language Studies 11.1, 119-142.

Thomas, J. 1995. Meaning in Interaction: An Introduction to Pragmatics. New York: Longman.

Weiss, J. \& M. Tschirhart. 1994. Public Information Campaigns as Policy Instruments. Journal of Policy Analysis and Management 13.1, 82-119.

Yule, G. 1996. Pragmatics. Oxford: OUP.

\section{Primary Sources}

Message 1. Action Project Poster. N.D. HIV and Disclosure. 
114 Pargmemes in Outdoor HIV/AIDS Campaign Messages in the Benin

Message 2. Action Project Poster. N.D. Avoid Stigma and Discrimination. N.D. Heart to Heart.

Message 3. HIV/AIDS Counselling Unit, University of Benin Teaching Hospital.

Message 4. Action Project Handbill. N.D. Love Carefully AIDS Has No Cure; Join Nigerian in the Fight against AIDS.

Message 5. Action Project Handbill. N.D. Zip Up.

Message 6. Action Project Poster. N.D. HIV/AIDS: Sexuality Transmitted Infections (STIs).

Message 7. USAIDS/Action Project Posters on HIV/AIDS. N.D. Safer Injection Prevents Infections.

Message 8. Action Project Poster. N.D. Prevention of Mother-toChild Transmission PMTCT.

Message 9. Billboard Advert on Highway in Benin Metropolis.

Message 10. Edo State Action Committee on AIDS Campaign Board.

Message 11. Action Project Poster. N.D. HIV/AIDS: Protect Yourself and Your Partner from HIV.

Message 12. Action Project Posters. N.D. An Activity of the Institute of Human Virology, Nigeria, CDC and Nigeria and Americans in Partnership to Fight HIV/AIDS.

Message 13. Action Project Posters. N.D. An Activity of the Institute of Human Virology, Nigeria, CDC and Nigeria and Americans in Partnership to Fight HIV/AIDS. 